\title{
Investigating the causes of examination anxiety and ways to reduce it among the Payame Noor University students south of the West Azerbaijan province
}

\author{
Siamand Movloudi ${ }^{1}$, Heman Mahmoudfakhe ${ }^{1, *}$ \\ Department of Psychology, Payame Noor University, PO BOX 19395 - 3697, Tehran, Iran \\ *E-mail address: hemanpsycho@yahoo.com
}

\begin{abstract}
The aim of the present research was to investigate the causes of examination anxiety and ways to reduce it among the Payame Noor University students south of the West Azerbaijan province. The universe under study was all the Payame Noor university students south of west Azerbaijan (Mahabad, Naghade, Piranshahr). They number around 12000 who were differentiated as 5401 boys and 6599 girls. The sample in question in this research was 300 people including 171 girls and 129 boys. The sampling method was a random-classification one. To collect data in this research, a researcher made questionnaire that included 32 questions as well as a standard 25 question questionnaire for the examination anxiety(Ahvaz) were used so as to measure the depending variable (examination anxiety). The research method was survey and for analyzing the data, the inferential statistics (Spearman correlation test and U Mann-Whitney test) were used. Findings revealed that there is a direct significant relationship among the familial life and examination anxiety, personality characteristics, environmental factors, quality of regulations and administration of examinations and both mental and bodily characteristics.
\end{abstract}

Keywords: Examination anxiety; Anxiety; Personality characteristics; Mental and bodily characteristics

\section{INTRODUCTION}

The phenomenon of anxiety is as old as the history of mankind .Since the old times when our ancestors were living in caves and because they for survival and subsistence, had to face all sorts of dangers and challenges until today that man has discovered all the oceans and galaxies around the universe, man has been grappling with anxiety. During the history with all its ups and downs, man has striven to obtain tranquility, security and emancipation from anxiety. Now, after 2 million years of the man creation on this earthly planet and reaching the zenith of technology and progress, we are still suffering from anxiety and insecurity and even we may say that the man's feeling of anxiety and concerns have gone up. The modern era is now called the era of anxiety (Khosravi \& Bigdeli, 2008). Our minds are always concerned with all that occulting around us and they warn us of the occurrences of the unpleasant and unfavorable events. The thinking of all natural people is equipped with a mechanism of 
"foresight" and "avoidance" that would make secure against things that might hurt us (Butler \& Hobb, 2001).

We can say with high confidence that it is impossible a man ever lives on this planet who has not yet tasted anxiety (Moani, 1990). One of the concerns of the educational system is the anxiety issue of the students that tolerating it is difficult for the students. Of course, the phenomenon of anxiety is not a grave issue and man has in all times experienced it. Anxiety plays a key role in peoples' lives and health. Anxiety and nervous pressures are the root cause of most physical problems and failures, but they cannot be eliminated and they exist forever and it is the physiology of the body that could expose the anxiety yields as debilitating or motivating (Moani, 1990). Examination anxiety is a property that is motivated through state, trepidation, and affectivity during the trend of examinations and assessments. It appears that the examination anxiety is a state of the general anxiety that consists of cognitive, behavioral and physiological responses relating to fear of failure, i.e. the examination anxiety is a grave negative emotion that involves behavioral and physiological and cognitive necessities. Any on experiences it under different conditions and subsequently most cognitive and attention processes are involved in the effective and efficient performance while doing the assignment (Karimvey, 2004). The examination anxiety as a determining factor affects the educational achievement of the students, thereby imposing hefty costs on the society as a whole (Karimvey, 2004).

\section{METHODOLOGY}

The research in question in accordance with the criterion of research objectives is a practical one. Also, due to the fact that through questionnaires, peoples' views are assessed, the method is done by way of survey. The universe under study was all the Payame Noor university students south of west Azerbaijan (Mahabad, Naghade, Piranshahr). They number around 12000 who were differentiated as 5401 boys and 6599 girls. The sample in question in this research was 300 people including 171 girls and 129 boys. The sampling method was a randomclassification one. Because the group we chose is all the male and female students of the PNU and all the participants in the research had equal chances for responding the questionnaires.

\section{1. Measuring tools}

To collect data in this research, a researcher made questionnaire that included 32 questions (questions 1-10 related to hypothesis 1; questions 11-15 related to hypothesis 2; questions 16-21 related to hypothesis 3; questions 22-30 related to hypothesis 4; and questions 31 and 32 related to hypothesis 5) as well as a standard 25 question questionnaire for the examination anxiety (Ahvaz) were used so as to measure the depending variable (examination anxiety). Questionnaires were close-ended answers and in multiple-choice forms whose measurement is Lickert scale. In the answers, choice never has one point, choice seldom has 2 points, choice sometime has 3 points and choice often times has 4 points (Abolghasemi \& Bokharian, 2000).

\section{RESULTS}

The research method was survey and for analyzing the data, the descriptive statistics (tables, graphs and appropriate indices) and also, the inferential statistics (Spearman correlation 
test and U Mann-Whitney test) were used. Here, in this part, we deal with the analysis of the data collected. First, to sum up and describe the data, the descriptive statistics (tables, graphs and appropriate indices) and the inferential statistics (Spearman correlation test and U MannWhitney test) were used .

Table 1. Correlation between family and parents' expectation of the students and their examination anxiety.

\begin{tabular}{|c|c|}
\hline Independent variable & $\begin{array}{c}\text { Family relation } \\
\text { (parents) }\end{array}$ \\
\hline Dependent variable & Spearman correlation coefficient $0 / 729$ \\
Examination anxiety & Sig.0/000 \\
& Sample volume 300 \\
\hline
\end{tabular}

Table (1) shows the correlation level between the family and parents' expectations of the students and their examination anxiety levels .As stated the correlation level was 0/729 between these two variables where they are significant at the $\alpha=0 / 01$ level. Hence, it can be said that the research hypothesis of ours is affirmed on the basis of these two variables.

Table 2. Correlation between personality characteristics of the students and their examination anxiety.

\begin{tabular}{|c|c|}
\hline Independent variable & Students' personality characteristics \\
\hline Dependent variable & Spearman correlation coefficient $0 / 814$ \\
\hline Examination anxiety & Sig. 0/000 \\
& Sample volume 300 \\
\hline
\end{tabular}

Table (2) shows the correlation level between the personality characteristics of the students and their examination anxiety levels .As stated the correlation level was $0 / 814$ between these two variables where they are significant at the $\alpha=0 / 01$ level. Hence, it can be said that the research hypothesis of ours is affirmed on the basis of these two variables.

Table 3. Correlation between the environmental factors of the students and their examination anxiety.

\begin{tabular}{|c|c|}
\hline Independent variable & Students' environmental factors \\
\hline Dependent variable & Spearman correlation coefficient $0 / 692$ \\
Examination anxiety & Sig. $0 / 000$ \\
& Sample volume 300 \\
\hline
\end{tabular}

Table (3) shows the correlation level between environmental factors of the students and their examination anxiety levels. As stated the correlation level was 0/692 between these two variables where they are significant at the $\alpha=0 / 01$ level. Hence, it can be said that the research hypothesis of ours is affirmed on the basis of these two variables. 
Table 4. Correlation between type of examination and regulations relating to the examination sessions of the students and their examination anxiety.

\begin{tabular}{|c|c|}
\hline Independent variable & $\begin{array}{c}\text { Students' type of examination and regulations } \\
\text { relating to the examination sessions }\end{array}$ \\
\hline Examination anxiety & $\begin{array}{c}\text { Spearman correlation coefficient } 0 / 727 \\
\text { Sig. } 0 / 000\end{array}$ \\
Sample volume 300
\end{tabular}

Table (4)s hows the correlation level between the type of examination and regulations relating to the examination sessions of the students and their examination anxiety levels .As stated the correlation level was $0 / 727$ between these two variables where they are significant at the $\alpha=0 / 01$ level. Hence, it can be said that the research hypothesis of ours is affirmed on the basis of these two variables.

Table 5. Correlation between type of examination and regulations relating to the examination sessions of the students and their examination anxiety.

\begin{tabular}{|c|c|}
\hline Independent variable & Students' bodily and mental characteristics \\
\hline Dependent variable & Spearman correlation coefficient $0 / 669$ \\
Examination anxiety & Sig. $0 / 000$ \\
& Sample volume 300 \\
\hline
\end{tabular}

Table (5) shows the correlation level between the bodily and mental characteristics of the students and their examination anxiety levels .As stated the correlation level was 0/669 between these two variables where they are significant at the $\alpha=0 / 01$ level. Hence, it can be said that the research hypothesis of ours is affirmed on the basis of these two variables.

Table 6. Statistical indices relating to the rankings of the variable of examination anxiety by differentiating two groups based on gender.

\begin{tabular}{|c|c|c|c|}
\hline Gender & No. & Average rankings & Sum of rankings \\
\hline Boy & 129 & $153 / 05$ & 19744 \\
\hline Girl & 171 & $148 / 57$ & 25406 \\
\hline
\end{tabular}


Table 7. Summary results of Mann-Whitney U test.

\begin{tabular}{|c|c|}
\hline U Mann -Whitney & 10700 \\
\hline Wilcoxon & 25406 \\
\hline$Z$ & $-0 / 446$ \\
\hline Sig. & $0 / 656$ \\
\hline
\end{tabular}

Due to the fact that the test significance is $0 / 656$ and is greater than $0 / 05$, hence we can say that the $\mathrm{H}_{0}$ off the test is supported and $\mathrm{H}_{1}$ is rejected. So we can claim that based on the research results, the variable of gender has had no effect on the variable of examination anxiety and the research hypothesis is rejected.

\section{CONCLUSIONS}

The correlation between the family and parents' expectations of the students and their examination anxiety is $0 / 729$ being significant at the $\alpha=0 / 01$ level. Hence, we can say that our research hypothesis is supported on the basis of these two variables. An inflexible pattern of educating the child, over expectation of the parents of the students and their perfectionism thinking, reproach and rebuke, lack of providing incentives and appropriate socio-economic states are considered as family factors. Parents sometimes send their children messages that would make them be anxious (Lets' see what you do, if you do not pass this test, you will have wasted all of our efforts and let's not forget your future hinges on this test ).

So, dear parents should boost the morale of their students and make not them be anxious. The Bolby's findings are in line with the results of this finding. Also, the findings of Khosravi and Bigdeli are in concert with these results (Robins, 2008). Also, the correlation between the personality characteristics of the students and their examination anxiety is $0 / 814$ being significant at the $\alpha=0 / 01$ level. Hence, we can say that our research hypothesis is supported on the basis of these two variables. People with lower self-esteem, have lower self-efficiency, experience failures and frustrations and have repeated anxieties and they are more likely prone to anxieties.

So, students must have strong self-confidence. The Isang's personality aspect is in line with this finding and so are those of the Khosravi and Bigdeli (Robins, 2008). Also, the correlation between the family and parents' expectations of the students and their examination anxiety is $0 / 692$ being significant at the $\alpha=0 / 01$ level. Hence, we can say that our research hypothesis is supported on the basis of these two variables. Children vulnerability might be due to environmental tensions compounded with lower socio-economic situations. Larger social environment, like schools are pivotal in the children prone to anxiety in pretending this disorder. Cultural factors too are effective in the children abilities to cope with stress. So, students should apply coping guidelines facing with examination anxiety severely and witness them objectively. Also, the correlation between the family and parents' expectations of the students and their examination anxiety is $0 / 727$ being significant at the $\alpha=0 / 01$ level. Hence, we can say that our research hypothesis is supported on the basis of these two variables. In relation to institute causes, we can refer to these case: Teachers' over expectations, difficult curricula, nature of examination (e.g. competitive aspect of it like Konkoor (entrance exam)), 
the exam invigilators being unfamiliar, time limitations, inappropriate examination environment, nuisance factors like noise and environment warmth, etc.... . Narimani's findings are in concert with the findings of this research (Narimani, 2006).

Also, the correlation between the family and parents' expectations of the students and their examination anxiety is $0 / 669$ being significant at the $\alpha=0 / 01$ level. Hence, we can say that our research hypothesis is supported on the basis of these two variables. So items that should be noted are as follow:

1. To give nerves to oneself

2. Attention while writing one's particulars

3. Increasing the level of accuracy

4. Giving importance to correct answers

5. Working relentlessly during the exam

6. Haste should not be made while answering

Also, due to the fact that the test significance is $0 / 656$ and is greater than $0 / 05$, hence we can say that the $\mathrm{H} 0$ off the test is supported and $\mathrm{H} 1$ is rejected. So we can claim that based on the research results, the variable of gender has had no effect on the variable of examination anxiety and the research hypothesis is rejected. In the end, students should adopt the following steps to cope with anxiety of exams: identify and correct irrational thoughts, 2 . find appropriate motivations for passing the test, 3. boost self-confidence and one's will, 4.use a coordinated program, 5. think of efforts and activities, 6. do no compare yourselves with others, 7 . identofy and correct the errors, 8. prepare a disciplined program for controlling anxiety, 9. assessment of the counseling centers for reforming an correcting the anxiety (Aghdasi, 2003).

\section{References}

[1] Abolghasemi A., Bokharian B., Psychological researches 5(4) (2000) 42-51.

[2] Aghdasi A. N. (2003). How can we win the (secret success). Tehran: publishing Sabzan.

[3] Butler G., Hobb T. (2001). Treating anxiety, Trans. By Koshyar Karimi Taromi, Tehran: Noandish publications.

[4] Karimvey M. (2004). Examining the effect of bodily relaxing practices on the anxiety level of the examination, Mazandaran journal of research scientific of the medical science university, Tehran.

[5] Khosravi M., Bigdeli I., Journal of behavioral sciences 1(3) (2008) 13-24.

[6] Moani I. (1990). Anxiety. Tehran: Chapakhsh Publications.

[7] Narimani M., Islamdoost S., Quarterly of research and planning of the higher education 39(12) (2006) 24-38.

[8] Robins P. (2008). Emancipation from anxiety, Trans, by Mohamad Samdani Fard.

Tehran: Arjomand publications.

[9] Hussein Meihami, International Letters of Social and Humanistic Sciences 8 (2013) 24-33. 
[10] Mohamad Khaledian, Zahra Ahmadimehr, Elham Naseri, Fakhralsadat Khosravani, Mojgan Shoshtsri, International Letters of Social and Humanistic Sciences 8 (2013) 43-48.

[11] Rezgar Mohammadi, Ezatullah Naderi, International Letters of Social and Humanistic Sciences 9 (2013) 22-30.

[12] Hussein Meihami, Bahram Meihami, Zeinab Varmaghani, International Letters of Social and Humanistic Sciences 11 (2013) 57-65.

[13] Akor Isaiah Akem, Victor Tavershima Ukeli, International Letters of Social and Humanistic Sciences 4 (2014) 49-59.

[14] Hamid Maleki, International Letters of Social and Humanistic Sciences 7 (2014) 62-66.

[15] Morteza Ziaee, International Letters of Social and Humanistic Sciences 9 (2014) 57-65.

[16] Mohamad Khaledian, Majid Omidi, Mandana Sepanta, Mehdi Tavana, International Letters of Social and Humanistic Sciences 9 (2014) 108-114.

[17] Sakineh Ghayazi, Faranak Omidian, Mohammed Hosseinpoor, International Letters of Social and Humanistic Sciences 10(1) (2014) 51-61.

[18] Heman Mahmoudfakhe, Morad Abdivarmazan, Toba Amini, International Letters of Social and Humanistic Sciences 15(2) (2014) 84-91.

[19] Roghaieh Fathi, International Letters of Social and Humanistic Sciences 19 (2014) 24-34.

[20] Hamid Kamarzarin, International Letters of Social and Humanistic Sciences 19 (2014) 69-80. 